\title{
CAPTURA Y ACONDICIONAMIENTO DE REPRODUCTORES DE CORVINA Cilus gilberti EN EL CENTRO DE ACUICULTURA MORRO SAMA - TACNA, PERÚ
}

\author{
CAPTURE AND CONDITIONING OF CORVINA BROOD STOCK Cilus \\ Gilberti AT THE AQUACULTURE CENTER MORRO SAMA - TACNA, PERU
}

${ }^{1}$ Luis Espinoza Ramos, ${ }^{2}$ Zumilda Contreras Mamani

\begin{abstract}
RESUMEN
El presente trabajo expone los resultados del desarrollo de un sistema de captura desde la naturaleza y acondicionamiento de ejemplares viables de Corvina (Cilus gilberti), para conformar un plantel de reproductores destinados a ser la base del cultivo inicial en cautiverio de este importante recurso marino de las costas del Pacífico sur. Se destaca en particular la óptima supervivencia en cautiverio de los ejemplares que conforman el plantel (100\% desde su captura hasta ya transcurridos los 7 meses de criados) y las estrategias para finalmente llegar al consumo de alimento $100 \%$ balanceado, lo que determina dejar de lado el alimento húmedo o el fresco.
\end{abstract}

Palabras clave: Alimentación, captura, cautiverio, Cilus gilberti, corvina.

\begin{abstract}
The present work, exposes the results of the development of a system of capture from the nature and conditioning of viable specimens of Corvina (Cilus gilberti), to conform a stock of reproducers, destined to be the base of an initial crop in captivity of this important marine resource of the pacific coasts. The optimum survival in captivity of the specimens that make up the establishment (100\% from Captura until after the 7 months reared) and the strategies to reach finally consumption of $100 \%$ balanced food, which determines the independence of the delivery of wet or fresh food stands out in particular.
\end{abstract}

Keywords: Feeding, capture, captivity, Cilus gilberti, croaker.

\section{INTRODUCCIÓN}

La acuicultura es una disciplina de la cual surgen distintas ramas, dependiendo del tipo de especie a cultivar, del ambiente y del espacio en el que sea capaz de desarrollarse (ANACAFÉ, 2004).

En los últimos cincuenta años la acuicultura se ha convertido en una actividad económica importante y tiene como finalidad una o varias de las siguientes actividades: producción de alimento nutritivo, obtención de compuestos de valor agregado, investigación, conservación y repoblamiento de especies $\mathrm{y}$ formación o recreación humana (Hasan $\mathrm{y}$ New, 2013; Radael, 2014; CIAD, 2017).
Las especies conocidas como esciénidos son comúnmente llamadas corvinas, tambores o roncadores, entre otras denominaciones. En inglés se conocen con los nombres de drum, croaker, jewfish, courbine blonde FAO (1992).

Cárdenas (2010) sostiene que las corvinas pertenecen específicamente a la familia Sciaenidae, que agrupa alrededor de 283 especies en 67 géneros.

Sus nombres vernáculos se relacionan con la capacidad que algunos tienen para hacer sonidos similares a un ronquido, cuando emplean su vejiga natatoria como una cámara de resonancia (Nelson et al., 2016).

\footnotetext{
${ }^{1}$ Ingeniero Pesquero. Facultad de Ciencias Agropecuarias. Universidad Nacional Jorge Basadre Grohmann. E-mail: laer54@hotmail.com

2Ingeniero Pesquero. Facultad de Ciencias Agropecuarias Universidad Nacional Jorge Basadre Grohmann. E-mail: czumilda@gmail.com 
Garcías et al. (2001) describen a la corvina como un pez marino, pelágico demersal, de hábitos neríticos, euritermo y eurihalino. Esta especie habita sobre la plataforma continental cerca de las áreas costeras poco profundas, en zonas de playa rompiente, caletas, orillas rocosas y fondos arenosos o fangosos, también se encuentra en aguas estuarinas.

Al respecto, Al-Okailee (2015) añade sobre estos peces que son predominantemente marinos y costeros, algunos temporalmente estuarinos y muy pocos dulceacuícolas, son carnívoros y forman cardúmenes.

Son buscados para la extracción de su vejiga natatoria, utilizada en la fabricación de colapez y como golosina oriental de alto valor comercial (Fischer et al., 1995; Cárdenas \& Gutiérrez, 2009). Las poblaciones de corvina han disminuido, además de que son vulnerables a ciertas condiciones climatológicas que resultan desfavorables para ellas, como el fenómeno de "El Niño" (Sielfeld et al., 2002). A nivel de industrialización, puede producirse a diferentes niveles: escala experimental, piloto comercial y comercial (rural o industrial) (FAO, 1983).

Esta investigación es de tipo experimental y tiene por objetivos: Desarrollar un sistema de captura de acondicionamiento de reproductores de corvina Cilus gilberti en el centro de acuicultura Morro Sama Tacna. Desarrollar una técnica de alta efectividad medida en sobrevivencia para la captura de ejemplares de corvina, en la región Tacna del Perú. Establecer una técnica de alimentación en cautiverio a los reproductores de corvina Cilus gilberti.

\section{MATERIAL Y MÉTODOS}

Para establecer el núcleo de reproductores se ha considerado la técnica de captura de animales en estado prepúber desde la naturaleza, específicamente desde la zona intermareal cercana a la localidad de Sama en el departamento de Tacna, Perú. El sitio de captura fue determinado en relación a la abundancia del recurso reportado por los lugareños y comprende la zona entre las playas Punta Colorada y Punta Mesa en la región de Tacna, distrito de Sama (latitud -18,0497 y longitud -70,8117); donde se procedió a la captura de 21 ejemplares de corvinas en tres jornadas, de acuerdo a la metodología que se describe a continuación.

Los animales capturados fueron mantenidos en sistemas de estanquería $-11 \mathrm{~m}^{3}$, estanques de fierro recubiertos con geomembranas de color negro de 1 metro de alto y 4 metros de diámetro- en las instalaciones del centro acuícola de Morro Sama dependiente del FONDEPES Perú (Fondo Nacional de Desarrollo Pesquero). En dichos estanques los animales fueron alimentados y evaluados en su desarrollo durante un periodo de 7 meses, hasta que consumieron alimento balanceado.

\section{Captura y transporte de reproductores}

Con la finalidad de obtener ejemplares salvajes de corvina Cilus gilberti, se realizaron 03 campañas de pesca.

La pesca de los especímenes se realizó en zona rocosa y arenosa marina de las playas de Punta Colorada y Punta Mesa (latitud - 18,0497 y longitud - 70,8117), a $50 \mathrm{~m}$ desde la línea de baja marea hacia el mar.

El aparejo empleado para la captura de los ejemplares consistió en el uso de cafias de pescar con anzuelos y carnada (figura 1).

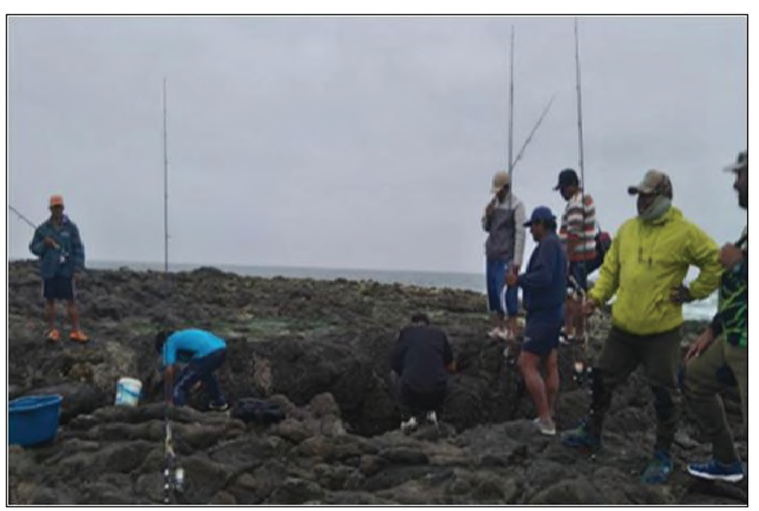

Figura 1. Captura de corvina con anzuelos.

Fuente: Imágenes propias.

La eliminación de anzuelos fue realizada por los mismos pescadores, para luego trasladar a las corvinas de forma inmediata a la orilla, donde se procedió a su evaluación física. Se las colocó en una tina oval de 501 , y alli se las reanimó con chorros de agua a través de un balde de 201 y jarras de 21 ; el agua empleada fue recogida de la playa, básicamente de la zona con notable presencia de corriente. Según la evaluación de los profesionales de campo, se procedió a la selección de los ejemplares que serían trasladados al centro acuícola de Morro Sama (figura 2).

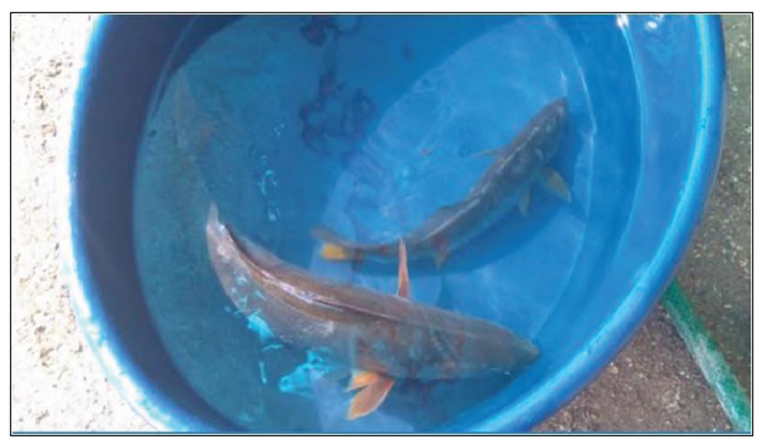

Figura 2. Recuperación de ejemplares capturados. Fuente: Imágenes propias. 
Una vez llegada la alta marea, el retiro de los pescadores o la obtención de 3 a más ejemplares, se procedió al traslado de los peces al centro acuícola de Morro Sama (17'59'39.7'S, 7052'59.1"O). El traslado se efectuó en un tanque cúbico de 10001 de capacidad de agua, instalado en una camioneta $4 \times 4$ y llenado hasta 4001 , en donde se suministró oxígeno puro desde un tanque metálico, conectado por una manguera de plástico trasparente y finalmente por una piedra difusora. La temperatura fue regulada durante la selección y transporte de ejemplares, por medio de bolsas con hielo de agua de mar de $1 \mathrm{~kg}$ aproximadamente introducidos al tanque de transporte, la temperatura se mantuvo en $15^{\circ} \mathrm{C}$.

Arribados los animales al centro acuícola, se inició el alimento a los 31 días de captura; en el mismo tanque de transporte se aplicó, por baño o inmersión a flujo detenido con aireación externa, el tratamiento preventivo con Oxitetraciclina genérica al $99 \%$ a una concentración $50 \mathrm{ppm}$, durante 1 hora.

\section{Acondicionamiento de reproductores}

Para que la etapa de acondicionamiento resultase exitosa, se procedió a tratamientos antiparasitarios preventivos durante un mes, mediante la aplicación de formol al $37 \%$ de pureza y a una relación de $1 \mathrm{ml}$ de formol por $6000 \mathrm{ml}$ de agua (1/6000 ppm). Esta etapa se llevó a caboen un tanque de $4 \mathrm{~m}$ de diámetro $\mathrm{y}$ 120001 de capacidad. El caudal de agua fue de 1,2 1/s (figura 3).

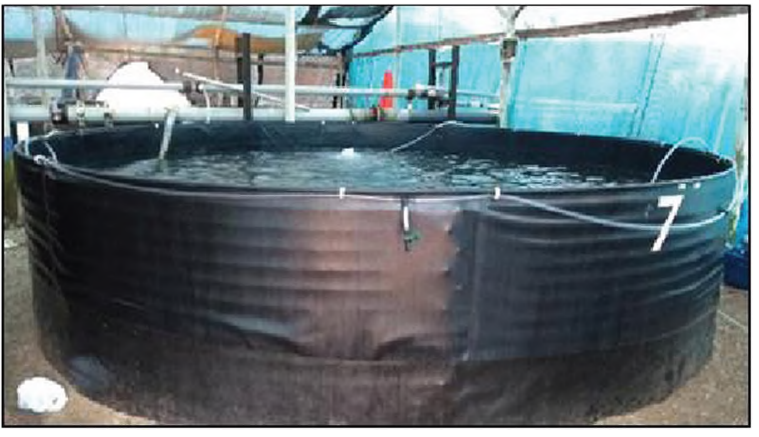

Figura 3. Acondicionamiento en tanque de $4 \mathrm{~m}$ de diámetro.

Fuente: Imnágenes propias.

La limpieza del tanque se realizó trasladando a las corvinas para vaciar luego el agua; posteriormente se procedió a la ejecución de barridos con escobas, la forma de barrido era en sentido radial: desde el borde interior del tanque hacia el centro, justamente donde se ubicaba la zona de desaguie. Esta limpieza se realizó a las 08:00 horas, dos veces por semana.

Los parámetros fisicoquímicos fueron registrados en el siguiente horario: 08:00, 12:00 y 16:00.

\section{Parámetros fisicoquímicos del agua}

Los parámetros fisicoquímicos fueron la temperatura del agua y del medio ambiente, así como el oxígeno disuelto en el agua. La temperatura del agua se tomó a las 08:00, 12:00, 14:00 y 16:00 horas de cada dia; del medio ambiente a las 09:00,12:00, 14:00 y 16:00; y con respecto al oxígeno disuelto en el agua, este se tomb tres veces al dia: a las 09:00, 12:00 y 16:00 horas con un oximetro YSI 550A(FONDEPES, 2015).

\section{Alimentación}

Al inicio del período de aclimatación, los primeros cuatro ejemplares de corvinas se mantuvieron en ayunas durante 31 días; los 5 siguientes ejemplares, 26 días de ayuno; y los 12 ejemplares restantes estuvieron en ayunas 23 días, para luego continuar con la siguiente secuencia:

1. A los ejemplares de corvina (Cilus gilberti) del primer grupo, desde el 4 hasta el 16 de julio de 2016, se les dio alimento fresco en cautiverio, específicamente el crustáceo decápodo Emerita analoga conocido en la región de Tacna como Muy-Muy $(4,367 \mathrm{~kg})$. Después de 31 días de la colecta se pudo observar restos de excretas de corvina con residuos de la especie Emerita analoga de color naranja, lo cual evidenció el consumo efectivo(figura 4).

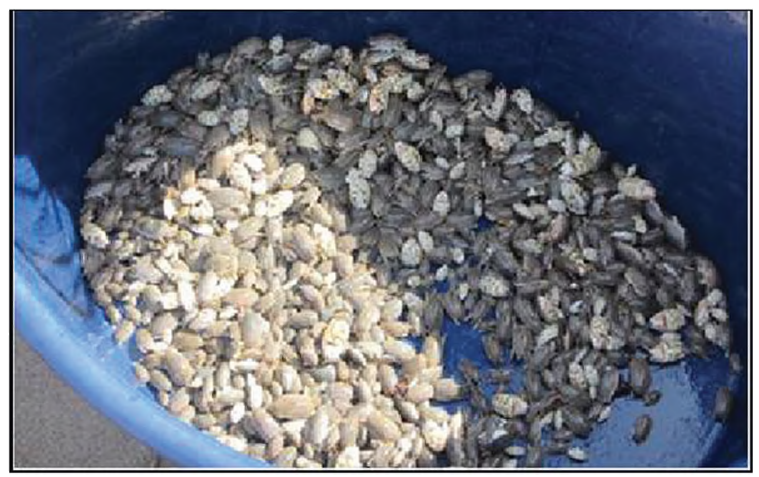

Figura 4. Muy-Muy (Emerita análoga).

Fuente:Imágenes propias.

2. A los ejemplares de corvina (Cilus gilberti) del segundo grupo, se les proporcionó 4,480 kilogramos de anchoveta Engraulis ringens congelada desde el 18 hasta el 28 de julio y los dias 01,02 y 11 de agosto de 2016; esto en horas de la noche entre las 20:00 y 21:00. Asimismo, se los alimentó con 19,162 kg de bonito Sarda chilensis chilensis, del 2 al 29 de setiembre, del 5 al 27 de octubre, del 2 al 29 de noviembre y del 1 al 29 de diciembre de 2016 (figura 5). 


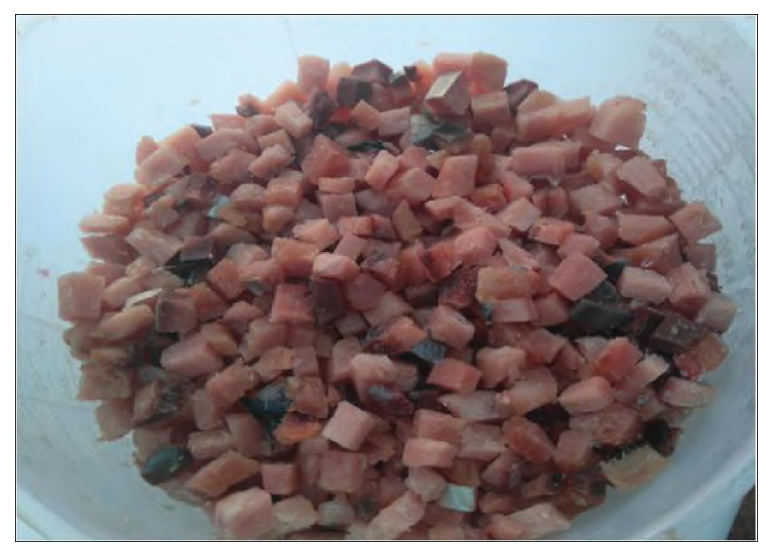

Figura 5. Bonito (Sarda chilensis chilensis). Fuente: Imágenes propias.

1. Es importante destacar que se les proporcionó 0,600 kg de Muy-Muy Emerita analoga con harina de pescado, del 12 al 13 de agosto de 2016; para dicha estrategia se seleccionó los Muy-Muy grandes. A1 suministrar dicho alimento se observó que lo aceptaron con normalidad.

En el caso de pellet húmedo (figura 6), este se incorporó a su dieta en una cantidad de $29,993 \mathrm{~kg}$, del 14 al 29 de agosto, del 1 al 30 de setiembre, del 1 al 29 de octubre, del 3 al 30 de noviembre y del 2 al 24 de diciembre de 2016. Con la finalidad de que se adapten a consumir alimento balanceado y posteriormente congelado, cuyos insumos que lo componen se detallan en la tabla 1.

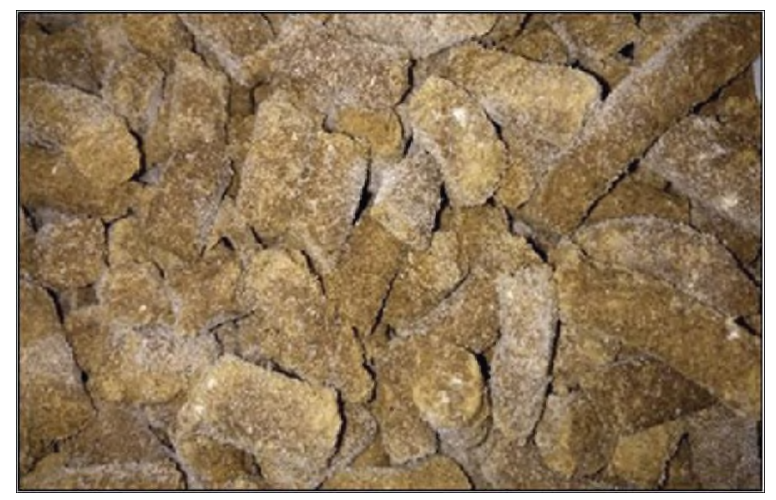

Figura 6. Pellet húmedo.

Fuente: Imágenes propias.
Tabla 1. Alimento balanceado, en forma de pellet húmedo para reproductores de la especie corvina (Cilus gilberti).

\begin{tabular}{llc} 
& \multicolumn{1}{c}{ Insumos } & Peso (g) \\
\hline & & \\
\hline & Harina de & \\
1 & Pescado & 6131,42 \\
2 & Torta de Soya & 2043,81 \\
3 & Harina de Trigo & 114,05 \\
4 & Aceite de Pescado & 1254,54 \\
5 & Colapez en polvo & 64 \\
\hline \multicolumn{3}{c}{ Vitaminas } \\
\hline 6 & Vitamina C & 50 \\
7 & Vitamina E & 4 \\
8 & Vitamina B & 44 \\
& & 146 \\
9 & Pecutrin & 10 \\
10 & Selco & 10 \\
11 & Metionina & 10 \\
12 & Treonina & 10 \\
13 & Lisina & 9892 \\
\hline
\end{tabular}

Fuente: Elaboración propia.

\section{Biometrías}

Este manejo, realizado mensualmente desde la llegada de los animales a la estación de Morro Sama, consistió en el pesado y medición de la talla de cada uno de los ejemplares de reproductores de corvina (Cilus gilberti).

\section{Identificación digital de las corvinas}

La identificación se realizó mediante un microchip o transponder, el cual fue implantado manualmente en la zona dorsal intramuscular, con la finalidad de tener un registro individual en cuanto al desarrollo biológico de los especímenes (figuras 7 y 8 ).

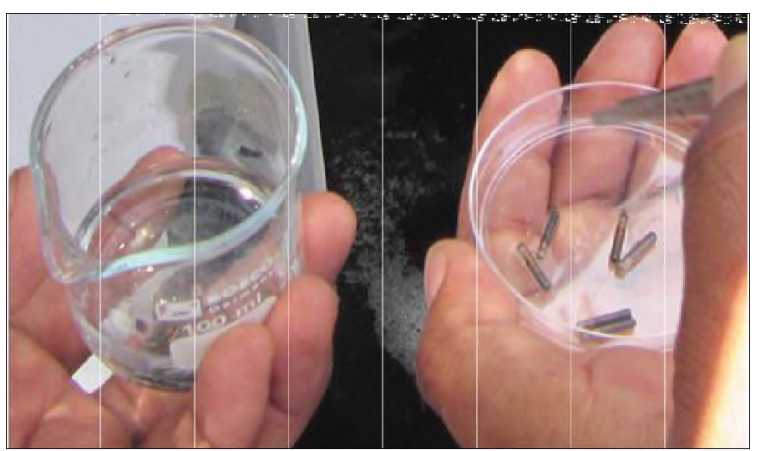

Figura 7. Microchip.

Fuente: Imágenes propias. 


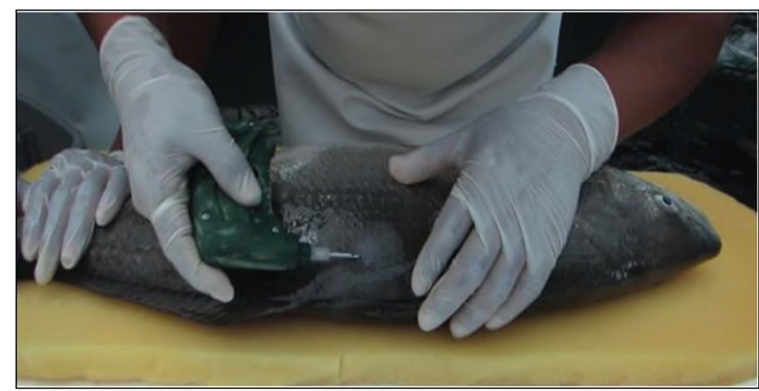

Figura 8. Implante de microchip.

Fuente: Imágenes propias.

\section{RESULTADOS}

Los ejemplares de corvina, una vez aclimatados y acondicionados, no presentaron mortalidad, la sobrevivencia fue al $100 \%$, como se puede observar en la tabla 2.

Tabla 2. Sobrevivencia de ejemplares capturados para plantel de reproductores.

\begin{tabular}{|c|c|c|c|c|c|}
\hline 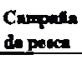 & Znone do Pesce & $\begin{array}{l}\text { Totil do } \\
\text { Cepotarndon }\end{array}$ & $\begin{array}{c}\mathbf{N}^{\mathbf{s}} \\
\text { maxtios }\end{array}$ & $\begin{array}{l}N^{\circ} \mathrm{do} \\
\text { sobrevivienter }\end{array}$ & $\begin{array}{c}\text { Sobrortivendn } \\
(\%)\end{array}$ \\
\hline 1 & Punta Colareda & 4 & 0 & 4 & 100 \\
\hline 2 & Punta Coloradis & $s$ & 0 & 5 & 100 \\
\hline 3 & Punta Masa & 12 & 0 & 12 & 100 \\
\hline Total & & 21 & $\overline{0}$ & 21 & 100 \\
\hline
\end{tabular}

Fuente: Elaboración propia.

Acondicionamiento de reproductores en cautiverio Para el acondicionamiento de los 21 ejemplares de corvina (Cilus gilberti) reproductoras en cautiverio, se procuró que la temperatura del agua se mantuviera entre 15,3 y $19,7^{\circ} \mathrm{C}$. Y la temperatura del ambiente, entre 15,7 y $25,4^{\circ} \mathrm{C}$ (figura 9).

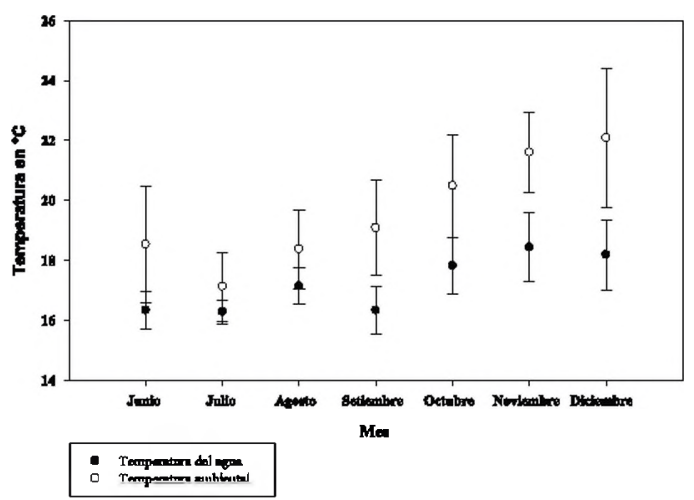

Figura 9. Registro de temperaturas $\left({ }^{\circ} \mathrm{C}\right)$ promedios y DS del agua y ambientales promedios. Estación Morro Sama, Tacna, (junio a diciembre 2016).

Fuente: Elaboración propia.
Dentro de los parámetros que se registraron para el acondicionamiento del cultivo de corvinas (Cilus gilberti), se suministró el oxígeno disuelto entre 5,65 y $8,09 \mathrm{mgL}^{-1}$ (figura 10)

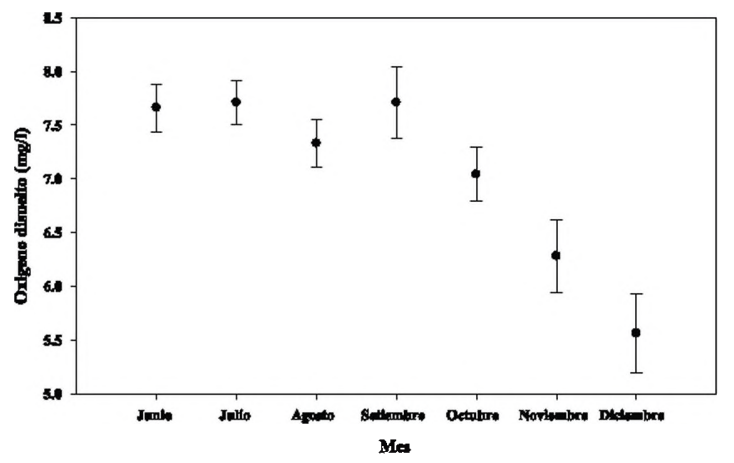

Figura 10. Registro de oxígeno disuelto (mg/l), promedios y DS. Tanque de cultivo. Centro de Acuicultura Morro Sama, Tacna. (Junio a diciembre 2016)

Fuente: Elaboración propia.

La figura 11 muestra el tipo de consumo de alimentos durante el desarrollo de este trabajo, específicamente durante la época de adaptación de las corvinas Cilus gilberti al sistema de confinamiento.

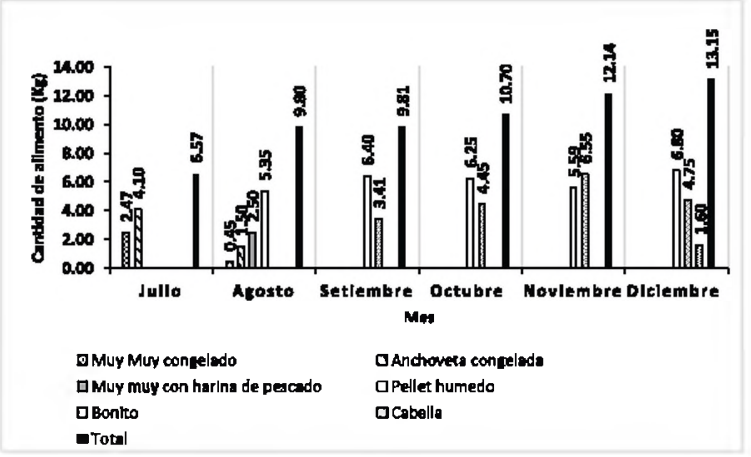

Figura 11. Registro de la cantidad de alimento proporcionado, fresco hasta pellet húmedo, durante los meses de acondicionamiento (julio a diciembre 2016). Fuente: Elaboración propia.

\section{DISCUSIÓN}

En el caso del acondicionamiento de la merluza austral (Merluccitus australis), Paillaman (2014), se utilizaron estanques de 2,5 $\mathrm{m}$ de altura y $3,88 \mathrm{~m}$ de diámetro, con tapa y equipados con luz interior; en el presente trabajo no se utilizó luz interior y la cubierta era de malla rachel al $75 \%$, lo que permite un ingreso mínimo de luz. Referente a la densidad, al inicio del acondicionamiento se utilizó una densidad de $4,17 \mathrm{~kg}$ $\mathrm{m}^{3}$ que se aproxima a la densidad de 3 a $4 \mathrm{~kg} / \mathrm{m}^{3}$ 
empleada por Paillaman (2014). El nivel de oxigeno coincide con lo indicado por el mismo autor, que es de $8,09 \mathrm{mg} / 1$. En cuanto al alimento vivo, no se le suministró pejerrey vivo ni tampoco sardina muerta, sino anchoveta Engraulis ringens.

En el periodo de acondicionamiento, se les proporcionó alimento a partir de los 31 días; sin embargo, autores como Pepe (2013) mencionan que no es necesario dejar muchos días sin alimento a los peces salvajes capturados y pasados a confinamiento, no obstante, hay experiencias de que se los ha dejado sin alimento hasta 3 meses (Morales, 2016); por lo que se debe tener en cuenta este periodo de ayuno.

De acuerdo a Silva (2010), para reproductores de cojinova del norte se acondicionaron dos sistemas: uno de recirculación y otro sistema abierto. En el presente trabajo solo se acondicionó un tanque en sistema abierto, por lo que en algunas oportunidades se tuvo problemas con el abastecimiento de agua, situación que no se presenta en un sistema con recirculación.

Según Jacumar (2018), los reproductores se mantienen en tanques de elevado volumen, a baja densidad y con agua salada de buena calidad y en un rango de temperatura dentro del óptimo $\left(14-24^{\circ} \mathrm{C}\right)$, indica además que la alimentación inicial se basa en sardina y calamar congelados, luego se pasa a proporcionar alimento seco para reproductores (rico en vitaminas y ácidos grasos esenciales). En esta investigación se optó por alimento fresco: anchoveta, bonito y caballa, que son especies ricas en ácidos grasos esenciales.

Según Jacumar, para la obtención de crías en cautividad es necesario crear y estabular un stock de reproductores, generalmente de origen salvaje, que son inducidos a la puesta mediante el uso de hormonas, por medio de inyección o implantes de liberación lenta. Los reproductores se mantienen en tanques de elevado volumen (de 20 a $250 \mathrm{~m}^{3}$ ), a baja densidad con agua salada de buena calidad y en un rango de temperatura dentro del óptimo de la especie $\left(14-24^{\circ} \mathrm{C}\right)$ pudiendo pesar entre 8 y 15 kilos. La alimentación inicial, tras la estabulación, se basa en sardina y calamar congelados para luego pasar a ser alimentados con pienso seco comercial diseñado para reproductores (rico en vitaminas y ácidos grasos esenciales).

Siguiendo a Muñoz, Segovia y Flores (2012), luego de 24 horas se evaluó la sobrevivencia de los reproductores y su estado sanitario; se les mantuvo en ayuno durante dos semanas -tiempo menor al empleado en este trabajo, el cual fue de 31 días-, los peces aceptaron el alimento ofrecido que contenía pejerrey de mar (Odontestesthes regia), moluscos (Photthaca thaca y Aylacomya ater), crustáceos (Grapsus grapsus), equinodermos (Loxechinus albus y Tetrapygur niger), entregados ad libitum. En cambio, en el presente trabajo no se agregaron ninguna de estas mezclas; otra diferencia es la densidad menor a la utilizada, que fue de $4,17 \mathrm{~kg} / \mathrm{m}^{3}$.
Con respecto a la sobrevivencia de los peces, IMARPE (2007) indica un 65\% luego de la captura y el acondicionamiento en cautiverio de la anchoveta (Engralulins ringens), otras investigaciones indican una sobrevivencia de $90 \%$. Cabe resaltar que, a la fecha de presentación de esta investigación, la sobrevivencia es del $100 \%$. Porcentaje óptimo si consideramos lo señalado por Reyes et al. (2012), para ejemplares de bacalao (Dissostichus eleginoides). Por otra parte, Smitt (1988), después de tres campañas de captura, obtuvo una sobrevivencia de $13 \%$ en promedio luego de tres años.

\section{CONCLUSIONES}

Se ha desarrollado una técnica de alta efectividad medida en una sobrevivencia del $100 \%$ tras la captura de ejemplares de corvina, en la región Tacna-Perú. La pesca con caña, además de ser un método selectivo, permite la sostenibilidad del recurso.

Se ha definido la alimentación de los reproductores de corvina en cautiverio en base a un alimento natural, en primer lugar, a fin de que posteriormente puedan consumir alimento balanceado (pellet húmedo).

\section{AGRADECIMIENTO}

Los autores expresan su agradecimiento al personal del FONDEPES (Fondo Nacional de Desarrollo Pesquero) Morro Sama-Tacna.

\section{REFERENCIAS BIBLIOGRÁFICAS}

Al-Okailee, M. (2015). Morphological and taxonomic study of eggs of some fish families with a reference to their abundance in the North West of Arabian Gulf. Mesopot. J. Mar. Sci.

ANACAFÉ (Asociación Nacional del café) (2004). Piscicultura. Programa de diversificación de ingresos en la empresa cafetalera. Guatemala. p.17. Recuperado de:

http://portal.anacafe.org/Portal/Documents/ Documents/2004-12/33/18/Piscicultura.pdf

Cárdenas, S. (2010). Crianza de la corvina (Argyrosomus regius), Cuadernos de Acuicultura 3. Madrid, España: Fundación OESA.

Cárdenas, S. y Gutiérrez C. (2009). Hoja divulgativa. Acuicultura mundial de corvinas. Fundación Observatorio Español de Acuicultura (Fundación OESA) y Sociedad Española de Acuicultura (SEA). IFAPA, El Puerto de Santa María, Cádiz. España.

CIAD (Centro de Investigación en Alimentación y Desarrollo A. C) (2017). Maestría y Doctorado en Ciencias. Tríptico Posgrado en Acuicultura. México. Recuperado de: http://www.ciad.mx/posgrados/images/docs/ tripticos_2017/TripticoAcuiculturafinal_ .pdf 
FAO (Organización de las Naciones Unidas para la Agricultura y la Alimentación). (1983). Niveles y modelos de la industria de la acuicultura. En: programa de desarrollo y coordinación de la acuicultura. Guía preliminar. Programa de las naciones unidas para el desarrollo. Recuperado de:

http://www.fao.org/docrep/x5743s/x5743s00 .htm\#Contents

FAO (Organización de las Naciones Unidas para la Agricultura y la Alimentación). (1992). Guía de campo de las especies comerciales marinas y de aguas salobres de la costa septentrional del sur de América. Fichas FAO de identificación de especies para los fines de la pesca. Recuperado de:

https://books.google.com.mx/books? id=hs hQKhnBs7kC\&printsec=frontcover\&source= gbs ge summarv $r \& c a d=0 \# v=0$ nepage \&a $\underline{\& f}=$ false

Fischer, W., Krupp, F., Schneider, W., Sommer, C., Carpenter K y Niem, V. (1995). Guía FAO para la identificación de especies para los fines de la pesca. Pacifico Centro-Oriental. Volumen III. Vertebrados-Parte 2- . Roma, 3.

FONDEPES (Fondo Nacional de Desarrollo Pesquero) (2015) Manual de Cultivo de Lenguado. Recuperado de: https://www.fondepes.gob.pe/src/manuales/ Manual-de-Cultivo-de-Lenguado.pdf

Garcías, F., Mendoza, R. y George, N. (2001). Variación entre años de la infracomunidades de parásitos metazoos de la corvina Cilus gilberti (Pisces: Sciaenidae) en Chile. Revista Chilena Historia Natural.

Hasan, M. y New M. (2013). On farm feeding and feed management in aquaculture. FAO Fisheries and Aquaculture Technical Paper.
IMARPE (Instituto del Mar del Perú) (2007). Informe, 34(3) Recuperado de: http://biblioimarpe.imarpe.gob.pe:808 0/bitstream/handle/123456789/1955/1 NF.\%2034(3).pdf?sequence $=$

JACUMAR (Junta Nacional Asesora de Cultivos marinos) (2018) Corvina Argyrosomus regius Recuperado de: www.mapama.gob.es/app/jacumar/especies/ Documentos/Corvina.pdf

Morales, A. (2016). Comunicación personal. Fondo Nacional de Desarrollo Pesquero. Centro de Acuicultura Morro Sama.

Muñoz, A., Segovia, E. y Flores, H. (2012). Latin American J. Aquat Res. International Conference: Environment and Resources of Th South Pacific. DOI: 103865/V. 140. Issue 3. Fulltex -18 .

Nelson, J., Grande T. y Wilson M. (2016). Fishes of the World. Hoboken, New Jersey, U.S.A.: John Wiley \& Sons Inc.

Paillaman, J., (2014). Comparación en la composición química corporal de reproductores salvajes de Merluza Austral (Merluccius australis) versus ejemplares sometidos al cautiverio. Puerto Montt, Chile.

Reyes, S. Kido, R, y Moreno, C (2012). Captura y mantención de Dissostichus eleginoides para conformar un plantel de reproductores. Scielo.

Sielfeld, W., Vargas M., Berrios V. \& Aguirre, G. (2002). Warm enso events and their effects on the coastal fish fauna of northern Chile. Investigaciones marinas, Supl. Symp.

Silva, A. (2010). Cultivo de cojinova en el norte de Chile. Revista Mundo acuícola y Pesquero. CONICYT. Ministerio de Educación Gobierno de Chile. 